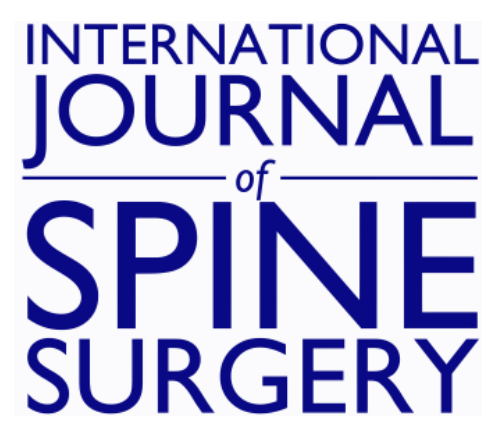

\title{
Relationship of Cervical Sagittal Vertical Alignment After Sagittal Balance Correction in Adult Spinal Deformity: A Retrospective Radiographic Study
}

SAKTHIVEL RAJAN MANOHARAN, DEEPAK JOSHI, MATT OWEN, STEVE M THEISS and DONALD DEINLEIN

Int J Spine Surg 2018, 12 (2) 269-275

doi: https://doi.org/10.14444/5033

http://ijssurgery.com/content/12/2/269

This information is current as of April 26, 2023.

Email Alerts Receive free email-alerts when new articles cite this article. Sign up at: http://ijssurgery.com/alerts 


\title{
Relationship of Cervical Sagittal Vertical Alignment After Sagittal Balance Correction in Adult Spinal Deformity: A Retrospective Radiographic Study
}

\author{
SAKTHIVEL RAJAN MANOHARAN, DEEPAK JOSHI, MATT OWEN, STEVE M. THEISS, \\ DONALD DEINLEIN \\ University of Alabama Medical Center, Birmingham, Alabama
}

\begin{abstract}
Study Design: Retrospective radiographic study.

Purpose: Predict the variability of the center of gravity of head (COG) relative to the global cervical sagittal alignment (SVA).

Background: Cervical lordosis, thoracic kyphosis, lumbar lordosis, and pelvic incidence are considered interrelated, with changes in SVA causing reciprocal changes to bring the head over pelvis. The implications of cervical deformities have generated more interest recently, and it has been shown that poor cervical alignment is associated with poor clinical outcomes.

Methods: Patients were selected from the imaging server of a single institution with adult spinal deformity (ASD) and SVA, who underwent surgical correction from 2008 to 2013. Three observers performed the measurements, and intraclass correlation coefficient (ICC) was measured for inter and intraobserver reliability. Group 1 was patients with unbalanced spines $(\mathrm{C} 7-\mathrm{SVA}>5 \mathrm{~cm})$ preoperatively and corrected to full balanced spine $(\mathrm{C} 7-\mathrm{SVA}<5 \mathrm{~cm})$ until last follow-up. Group 2 was improved in sagittal balance after surgery and maintained SVA correction until last follow-up, but not fully balanced.

Results: Fifty-five patients met the inclusion criteria, 42 patients improved in SVA after surgery, and 13 showed no improvement. Twenty-three patients kept full balanced measurements until last follow-up, and 19 patients maintained not-full balanced spine. In group 1, there was no change in pre and postoperative parameters except for C2CL $\left(21.74^{\circ}\right.$ vs $\left.16.91^{\circ}, P=.033\right)$. It was similar in group 2 , no differences except for C2-CL $\left(21.67^{\circ}\right.$ vs $\left.17.81^{\circ}, P=.018\right)$.

Conclusion: Parameters in this study failed to yield predictable relationships when compared to changes in SVA. The position of COG may be independent of global SVA.

Clinical Relevance: This study aims to improve our understanding of the dynamic changes and relationships of the regional and global spinal parameters with regard to spinal deformity corrective surgeries in adults.

Level of Evidence: III.

Other Special Categories

Keywords: cervical spinal parameters, cervical sagittal balance, adult spine deformity, sagittal vertical alignment, center of gravity
\end{abstract}

\section{INTRODUCTION}

The cervical spine is a complex region, as it not only supports the mass of the head, but also allows the widest range of motion relative to the rest of the spine. Cervical lordosis, thoracic kyphosis, lumbar lordosis, and pelvic incidence are considered interrelated, with changes in cervical sagittal alignment causing reciprocal changes in the other parameters to bring the head over the pelvis and vice-versa. ${ }^{1-3}$ The implications of cervical deformities have generated more interest recently, ${ }^{3-5}$ and it has been shown that poor cervical alignment is associated with poor clinical outcomes. 6 ,7

In patients with a degenerative spine, the interrelation of pelvic parameters, lumbar lordosis, thoracic kyphosis, sagittal imbalance, and its effect on quality of life and patient outcome has been well established. ${ }^{8,9}$ The studies on interrelation of local cervical parameters and global sagittal balance in patients with degenerative spinal deformities are relatively few.

We hypothesized that in patients suffering from adult degenerative spine deformities (ASD) with an unbalanced spine, the center of the cervical seven 


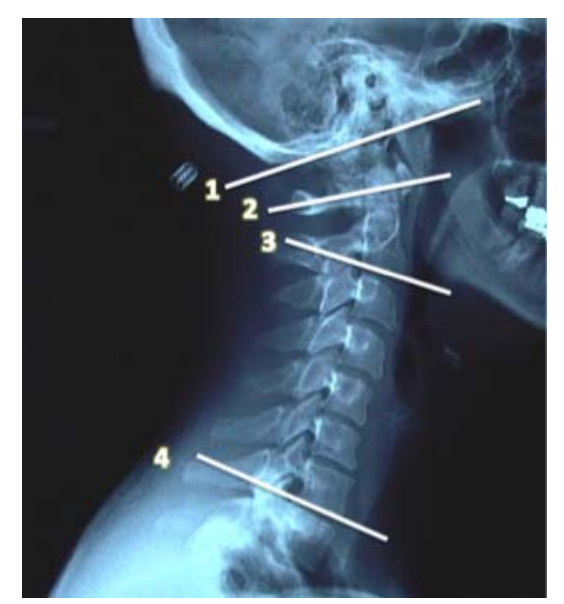

Figure 1. Occipito-cervical lordosis: angle between line 1 and 4 . $C 1$ to $C 7$ cervical lordosis: angle between line 2 and 4. C2 to C7 cervical lordosis: angle between line 3 and 4 .

vertebrae (C7) is shifted anteriorly with respect to the sacrum; thus, the cervical spine will make adjustments to place the center of gravity of the head over the sacrum. When there is improvement in the spinal balance after deformity correction and the center of $\mathrm{C} 7$ is brought back over the sacrum, the compensatory cervical adjustments will reverse. The aim of this study was to predict the variability of the center of gravity of the head relative to the global sagittal alignment.

\section{PATIENTS AND METHODS}

This was a retrospective radiographic study of patients with ASD with documented sagittal or coronal imbalance, from one institution between 2008 and 2013. After obtaining institutional review board approval, the patients were evaluated for age, sex, surgical technique, and duration of follow-up. The inclusion criteria used for candidates were patients with adult degenerative spine disease with preoperative sagittal imbalance having operative intervention for spinal deformity correction with at least 2-year postoperative follow-up. Patients with any restriction in neck range of motion on history or physical examination and those with prior fusion of the cervical spine (surgical, inflammatory, or congenital) were excluded.

The choice of the surgical procedure for correction of the deformity in patients with ASD was according to the surgeon's preference. The exclusion criteria were a sagittal deformity secondary to a known etiology, previous cervical spine surgery, and nonavailability of lateral roentgenograms, which visualize the occiput and the femoral heads.

A standard 3-foot anterior-posterior (AP) and lateral roentgenogram was obtained for each patient. To obtain the lateral view, the patient stood with knees extended, looking straight ahead and with fingertips on clavicles and elbows flexed. Tube to subject distance was 72 inches in each patient. Three observers performed each of the selected measurements and inter and intraobserver reliability coefficients were measured to assess conformity amongst observers (Table 1). ${ }^{10,11}$

The Cobb angle method ${ }^{12}$ was used to measure the OC-C7, C1-C7, and C2-C7 lordosis. The first is a horizontal line drawn from base of the occiput, the second horizontal line is drawn extending from the anterior tubercle of $\mathrm{C} 1$ to the posterior margin of the spinous process of the same vertebra, the third horizontal line is drawn parallel to the inferior endplate of $\mathrm{C} 2$, and the fourth horizontal line is drawn parallel to the inferior endplate of $\mathrm{C} 7$. The angle subtended between the perpendiculars to the above lines is the cervical lordotic angle. The angle between the first and fourth line is designated OC$\mathrm{C} 7$ lordosis (OC CL), the angle between the second and fourth line being C1-C7 lordosis (C1 CL), and the angle between the third and fourth line being C2-C7 lordosis (C2 CL) (Figure 1).

The center of gravity of the head (COG) plumb line is drawn from the anterior portion of the external auditory canal as the initial point. The $\mathrm{C} 2$ sagittal plumb line is drawn with a lateral gravity plumb line from the center of $\mathrm{C} 2$; the center of $\mathrm{C} 2$ was noted by the intersection of crossing diagonals of the vertebral body of $\mathrm{C} 2$ on the lateral radiograph. The $\mathrm{C} 7$ sagittal plumb line is drawn

Table 1. Inter- and intraobserver reliability coefficient, intraclass correlation coefficient (ICC).

\begin{tabular}{|c|c|c|c|c|}
\hline Radiographic Parameter & Interobserver ICC (95\% CI) & Observer 1 ICC (95\%) & Observer 2 ICC (95\%) & Observer 3 ICC (95\%) \\
\hline C2-C7 SVA & $0.82(0.67-0.91)$ & $0.99(0.98-1.00)$ & $0.95(0.86-0.98)$ & $0.97(0.91-0.99)$ \\
\hline COG-C7 SVA & $0.89(0.79-0.95)$ & $0.91(0.77-0.97)$ & $0.98(0.94-0.99)$ & $0.96(0.89-0.98)$ \\
\hline OC CL & $0.95(0.89-0.98)$ & $0.99(0.98-1.00)$ & $0.99(0.97-1.00)$ & $0.93(0.82-0.97)$ \\
\hline $\mathrm{C} 1 \mathrm{CL}$ & $0.61(0.40-0.79)$ & $0.88(0.70-0.96)$ & $0.78(0.53-0.92)$ & $0.80(0.56-0.93)$ \\
\hline $\mathrm{C} 2 \mathrm{CL}$ & $0.75(0.56-0.87)$ & $0.95(0.88-0.98)$ & $0.90(0.75-0.96)$ & $0.85(0.65-0.94)$ \\
\hline
\end{tabular}

Abbreviations: SVA, sagittal vertical axis; COG, center of gravity of head; OC CL, occipito-cervical lordosis; C1 CL, C1-C7 lordosis; C2 CL, C2-C7 lordosis. 


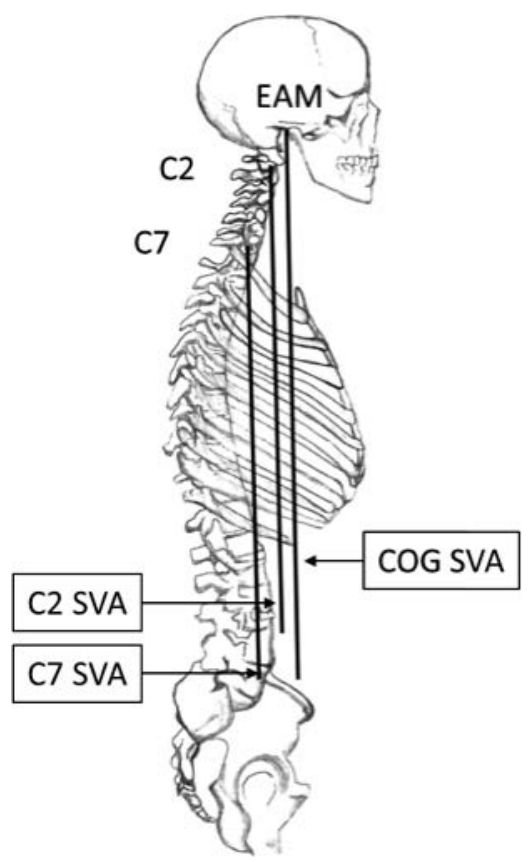

Figure 2. Measurement of center of gravity of head (COG), C2, and C7 sagittal vertical axis (SVA).

with a lateral gravity plumb line from the center of $\mathrm{C} 7$; the center was noted similar to $\mathrm{C} 2$. The distance between the plumb lines was measured as the shortest perpendicular distance between the 2 lines. C7 SVA was measured by using the distance of the C7 plumb line from the posterior-superior aspect of sacrum (Figure 2).

COG-C7 sagittal vertical axis (SVA) was measured regionally using the distance between a plumb line dropped from the COG (COG SVA) and the posterior superior aspect of C7. Similarly, C2-C7 SVA (C2 Regional SVA) was measured regionally using the distance between a plumb line dropped from the centroid of $\mathrm{C} 2$ (odontoid) and the posterior superior aspect of $\mathrm{C} 7$ (Figure $3 \mathrm{a}$ and $3 \mathrm{~b}$ ).

Balanced spines were defined as spines with $\mathrm{C} 7$ SVA $<5 \mathrm{~cm}$ and unbalanced spines those with $\mathrm{C} 7$ $\mathrm{SVA} \geq 5 \mathrm{~cm} .{ }^{4,8,9}$ Using this criterion, we divided subjects into 2 groups. Group 1 patients corrected to fully balanced axis until last follow-up, where balanced spines had C7 SVA less than $5 \mathrm{~cm}$. Correspondingly, group 2 comprised patients who improved in sagittal balance after surgery and maintained SVA correction until last follow-up, but were not fully balanced. Preoperative and postoperative regional cervical spine data (ie, C2C7 SVA, COG-C7 SVA, OC CL, C1 CL, and C2 CL) from each group were compared using the paired $t$-test using SPSS software.
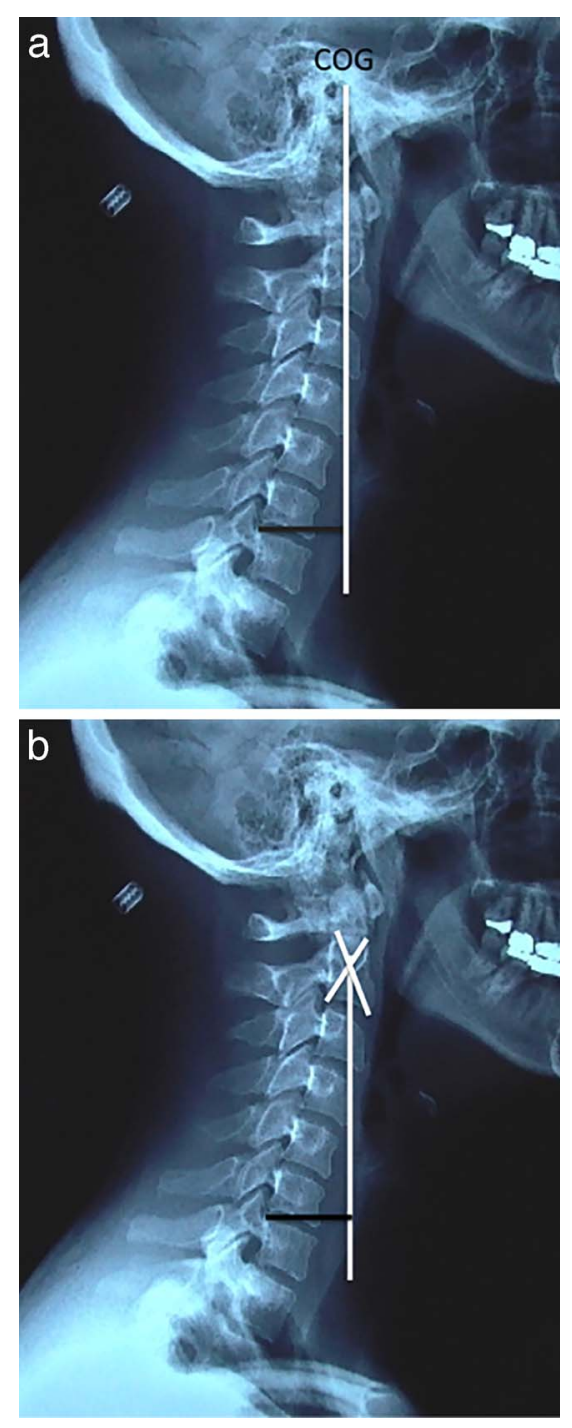

Figure 3. ( $a$ and $b$ ) Measurement of regional center of gravity of head (COG)C7 sagittal vertical axis (SVA) and C2-C7 SVA.

The common cervical and spino-pelvic parameters used and described in the study are defined in Table 2.

\section{RESULTS}

Fifty-five patients met the inclusion criteria for our study, from which 45 were females and 10 were males. The mean age was 68.2 years (range $43-84$ years). The mean follow-up was 60.7 months (range 27-98 months.) Forty-two patients showed improvement after surgery in sagittal balance, and 13 showed no improvement. Twenty-three patients kept balanced measurements until last follow-up (group 1); the rest included group 2. Intraclass correlations coefficient (ICC) for inter and intraobserver reliability were good, with values ranging 
Table 2. Description of spinal and pelvic parameters.

\begin{tabular}{|c|c|c|}
\hline Parameter & Abbreviation & Description \\
\hline Sagittal vertical axis & SVA & $\begin{array}{l}\text { A vertical line from center of the 7th cervical vertebra. The distance of this line from the posterior sacral } \\
\text { endplate determines sagittal balance. }\end{array}$ \\
\hline Pelvic tilt & PT & $\begin{array}{l}\text { The angle between the line joining the midpoint of the sacral end plate to the midpoint of the } \\
\text { bicoxofemoral axis and the vertical. }\end{array}$ \\
\hline Sacral slope & SS & Angle of the sacral endplate with the horizontal. \\
\hline Pelvic incidence & PI & $\begin{array}{l}\text { Angle between a line drawn perpendicularly to the sacral endplate at its midpoint and the line joining the } \\
\text { center of the femoral heads (midpoint of bicoxofemoral axis) to the same midpoint of sacral endplate. }\end{array}$ \\
\hline Lumbar lordosis & LL & $\begin{array}{l}\text { The measure of the angle measured by Cobb's method from the sacral endplate to the inferior endplate of } \\
\text { the thoracic } 12 \text { vertebrae. }\end{array}$ \\
\hline Thoracic kyphosis & TK & $\begin{array}{l}\text { The measure of the angle measured by Cobb's method between the superior endplate of the most clearly } \\
\text { visible uppermost kyphotic thoracic vertebra and the inferior endplate of the thoracic } 12 \text { vertebrae or } \\
\text { lowermost kyphotic vertebra. }\end{array}$ \\
\hline Thoracic inlet angle & TIA & $\begin{array}{l}\text { TIA has been defined as the angle between a line originating from the center of the } \mathrm{T} 1 \text { endplate and } \\
\text { perpendicular to the } \mathrm{T} 1 \text { endplate and a line from the center of the T1 endplate and the upper end of the } \\
\text { sternum. }\end{array}$ \\
\hline $\mathrm{T} 1$ pelvic angle & TPA & $\begin{array}{l}\text { Defined as the angle between the line from the femoral head axis to the centroid of } \mathrm{T} 1 \text { and the line from } \\
\text { the femoral head axis to the middle of the S1 endplate. }\end{array}$ \\
\hline T1 slope & T1S & The angle between the superior endplate of the first thoracic vertebra and the horizontal. \\
\hline
\end{tabular}

from 0.61 to 0.95 and 0.78 to 0.99 , respectively (Table 1).

In group 1 (Table 3; Figure 4a and 4b), there was no significant change in preoperative and postoperative C2-C7 SVA, COG-C7 SVA, OC CL, and C1 CL. There was a statistically significant change in C2 CL; from a preoperative mean $21.74^{\circ}$ to a postoperative mean $16.91^{\circ}(P=.033)$, a change of $4.83^{\circ}$. Similarly, in group 2 (Table 4; Figure 5a and $5 b)$, there was no significant change in preoperative and postoperative C2 SVA, COG-C7 SVA, OC CL, and $\mathrm{C} 1 \mathrm{CL}$. There was a statistically significant change in $\mathrm{C} 2 \mathrm{CL}$; from a preoperative mean $21.67^{\circ}$ to a postoperative mean $17.81^{\circ}(P=.018)$, a change of $3.86^{\circ}$. In group 2, there was an increase in the Regional C2 SVA (C2-C7 SVA), nearing statistical significance $(P=.055)$ from a mean of $27.32 \mathrm{~mm}$ preoperative to $32.55 \mathrm{~mm}$ postoperative, with a difference of $5.23 \mathrm{~mm}$.

\section{DISCUSSION}

Over the last decade, it has been increasingly recognized that sagittal spino-pelvic alignment is a

Table 3. Group 1 results.

\begin{tabular}{lccc}
\hline $\begin{array}{l}\text { Radiographic } \\
\text { Parameter }\end{array}$ & $\begin{array}{c}\text { Preoperative } \\
\text { (Mean } \pm \text { SD) }\end{array}$ & $\begin{array}{c}\text { Postoperative } \\
\text { (Mean } \pm \text { SD) }\end{array}$ & $\boldsymbol{P}$ Value \\
\hline C2-C7 SVA & $26.44 \pm 16.37$ & $32.43 \pm 14.65$ & .092 \\
COG-C7 SVA & $22.35 \pm 25.52$ & $25.52 \pm 21.59$ & .637 \\
OC CL & $60.64 \pm 13.92$ & $60.24 \pm 13.56$ & .787 \\
C1 CL & $44.39 \pm 17.97$ & $45.09 \pm 14.77$ & .808 \\
C2 CL & $21.74 \pm 16.88$ & $16.91 \pm 13.84$ & $\mathbf{. 0 3 3}$ \\
\hline
\end{tabular}

Abbreviations: SVA, sagittal vertical axis; COG, center of gravity of head; OC CL, occipito-cervical lordosis; C1 CL, C1-C7 lordosis; C2 CL, C2-C7 lordosis; $\mathrm{SD}$, standard deviation.

Bold indicates statistical significance $(P<.05)$. complex chain of correlations from the pelvis to occiput and that changes in 1 region of the spine, such as with instrumented fusion for deformity correction, can result in reciprocal changes in the spino-pelvic regions leading to potential alignment consequences. The reciprocal changes in cervical lordosis after deformity correction has been described previously ${ }^{4}$; but changes in regional cervical SVA, position of COG of head, and OC-CL and C1-CL have not been described previously.

In the present study, we hypothesized that position of the center of gravity of the head is the main determinant of global sagittal balance in that the body always attempts to bring the center of the head over the sacrum. Thus, in an unbalanced spine, in order to place the center of gravity of the head over the sacrum, there will be an increase in cervical lordosis and a compensatory decrease in both COGSVA and C2SVA. In addition, when there is improvement in the spinal balance after deformity correction, the cervical lordosis will decrease and both COG-SVA and C2SVA will have a compensatory increase.

Table 4. Group 2 results.

\begin{tabular}{lccc}
\hline $\begin{array}{l}\text { Radiographic } \\
\text { Parameter }\end{array}$ & $\begin{array}{c}\text { Preoperative } \\
\text { (Mean } \pm \text { SD) }\end{array}$ & $\begin{array}{c}\text { Postoperative } \\
\text { (Mean } \pm \text { SD) }\end{array}$ & $\boldsymbol{P}$ Value \\
\hline C2-C7 SVA & $27.32 \pm 17.79$ & $32.55 \pm 17.22$ & .055 \\
COG-C7 SVA & $27.10 \pm 32.68$ & $27.29 \pm 31.51$ & .973 \\
OC CL & $58.18 \pm 16.12$ & $58.76 \pm 15.48$ & .800 \\
C1 CL & $48.44 \pm 16.62$ & $45.43 \pm 13.82$ & .242 \\
C2 CL & $21.67 \pm 14.93$ & $17.81 \pm 12.53$ & $\mathbf{. 0 1 8}$ \\
\hline
\end{tabular}

Abbreviations: SVA, sagittal vertical axis; COG, center of gravity of head; OC CL, occipito-cervical lordosis; C1 CL, C1-C7 lordosis; C2 CL, C2-C7 lordosis; $\mathrm{SD}$, standard deviation.

Bold indicates statistical significance $(P<.05)$. 

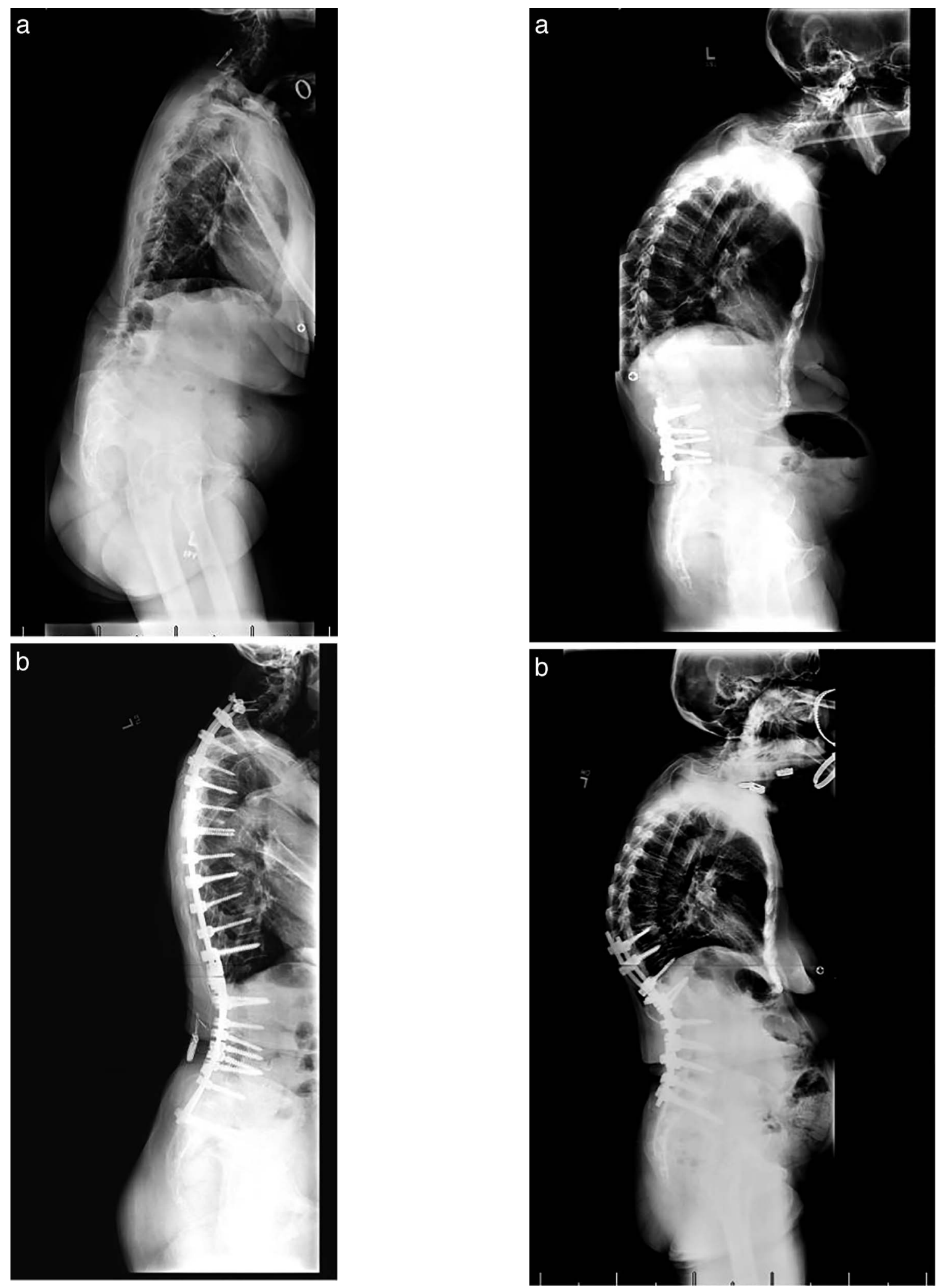

Figure 4. ( $a$ and $b$ ) Example of group 1 patient. Preoperative unbalanced spine is balanced postoperative until last follow-up with less than $5 \mathrm{~cm}$.

Figure 5. ( $\mathrm{a}$ and $\mathrm{b}$ ) Example of group 2 patient. Preoperative unbalanced spine is balanced postoperative until last follow-up with greater than $5 \mathrm{~cm}$ 
Normal values of local cervical parameters have already been established. In asymptomatic volunteers a large percentage (approximately 75\%-80\%) of cervical standing lordosis is localized to C1-2 and relatively little lordosis exist in the lower cervical levels. ${ }^{13,14}$ Cervical lordosis normally increases with age and average lordosis in cervical spine is from $22^{\circ}$ to $25^{\circ}$ in volunteers age 50 to $65 .{ }^{15}$ The mean cervical lordosis in unbalanced patients was $21.67^{\circ}$ in our study, which is within normal limits, suggesting that cervical lordosis is unchanged in unbalanced spines. The average odontoid-C7 plumb line distance in normal healthy volunteers ranges from 15 to $17 \mathrm{~mm} \pm 11.2 \mathrm{~mm}$. The mean Regional C2 SVA in unbalanced patients in our study was $27.32 \mathrm{~mm}$, which is above normal values of 15 to $17 \mathrm{~mm}$. This is contrary to our hypothesis, where we assumed that regional C2 SVA should be decreased in unbalance patients in order to bring the COG of the head over the sacrum, suggesting that possibly cervical lordosis and COG of the head may be independent variables.

There is no significant change in COG-C7 SVA in either group in our study (Tables 3 and 4), suggesting that head position is not affected by sagittal imbalance. This we believe is because of the major contribution in lordosis at the cranio-cervical junction and at C1-C2 level. Similarly, there is no significant change in C2-C7 SVA or OC CL in either group. However, there is a decrease in $\mathrm{C} 2-\mathrm{C} 7 \mathrm{CL}$ from preoperative to postoperative in both the groups. This is in agreement with Smith et $\mathrm{al}^{4}$ who demonstrated that cervical lordosis makes reciprocal changes with sagittal alignment. This occurs to bring $\mathrm{C} 2$ vertebra in optimal inclination for effective transfer of weight of head while maintaining horizontal gaze, with minimal expenditure of energy. Compensation for horizontal gaze can be made at $\mathrm{C} 1-2$ junction, but acute compensation at that level will be uncomfortable and energy inefficient.

In conclusion, the cervical spine parameters in this study failed to yield predictable relationships when compared to changes in SVA. The small increase in regional C2 SVA postoperative patients and the decrease in $\mathrm{C} 2$ to $\mathrm{C} 7 \mathrm{CL}$, suggest small adaptive changes of cervical spine to maintain horizontal gaze. Thus, in patients with ASD with sagittal imbalance the cervical spine does not compensate for position of the head over the pelvis and the position of center of gravity of head is independent of global sagittal alignment. Our perspective is that the cervical subaxial sagittal parameters are dependent on the anatomy of the cervicothoracic junction (T1 slope) as corroborated in the study by Lee et $\mathrm{al}^{16}$ rather than global sagittal imbalance. However, as our study is retrospective, it does have significant limitations, which include levels and fusion techniques used are varied in each patient which could subsequently have affected the cervical spine parameters measured. Preoperative neck disability index data and complete physical examination of cervical spine were not available as this was a retrospectively collected data. The relation of thoracic inlet angle, T1-slope, TPA, and cervical alignment needs to be better elucidated in future studies.

\section{REFERENCES}

1. Scheer JK, Tang JA, Smith JS, et al. Cervical spine alignment, sagittal deformity, and clinical implications: a review. J Neurosurg Spine. 2013;19(2):141-159.

2. Weng C, Wang J, Tuchman A, et al. The influence of T1 slope on the cervical sagittal balance in degenerative cervical spine: an analysis using kinematic MRI. Spine (Phila Pa 1976). 2016;41(3):185-190.

3. Smith JS, Lafage V, Schwab FJ, et al. Prevalence and type of cervical deformity among 470 adults with thoracolumbar deformity. Spine (Phila Pa 1976). 2014;39(17):E1001E1009.

4. Smith JS, Shaffrey CI, Lafage V, et al. Spontaneous improvement of cervical alignment after correction of global sagittal balance following pedicle subtraction osteotomy. $J$ Neurosurg Spine. 2012;17(4):300-307.

5. Vadgaonkar R, Murlimanju BV, Pai MM, Prabhu LV, Goveas AA, Kumar S. Cervical spine synostosis: an anatomical study with emphasis on embryological and clinical aspects. Clin Ter. 2012;163(6):463-466.

6. Tang JA, Scheer JK, Smith JS, et al. The impact of standing regional cervical sagittal alignment on outcomes in posterior cervical fusion surgery. Neurosurgery. 2015;76(Suppl 1):S14-S21; discussion S.

7. Protopsaltis TS, Scheer JK, Terran JS, et al. How the neck affects the back: changes in regional cervical sagittal alignment correlate to HRQOL improvement in adult thoracolumbar deformity patients at 2-year follow-up. J Neurosurg Spine. 2015;23(2):153-158.

8. Schwab F, Farcy JP, Bridwell K, et al. A clinical impact classification of scoliosis in the adult. Spine (Phila Pa 1976). 2006;31(18):2109-2114.

9. Glassman SD, Berven S, Bridwell K, Horton W, Dimar JR. Correlation of radiographic parameters and clinical symptoms in adult scoliosis. Spine (Phila Pa 1976). 2005;30(6):682-688.

10. Tauchi R, Tsuji T, Cahill PJ, et al. Reliability analysis of Cobb angle measurements of congenital scoliosis using X-ray and 3D-CT images. Eur J Orthop Surg Traumatol. 2016;26(1):53-57. 
11. Wu W, Liang $\mathrm{J}, \mathrm{Du} \mathrm{Y}$, et al. Reliability and reproducibility analysis of the Cobb angle and assessing sagittal plane by computer-assisted and manual measurement tools. BMC Musculoskelet Disord. 2014;15:33.

12. Harrison DE, Harrison DD, Cailliet R, Troyanovich SJ, Janik TJ, Holland B. Cobb method or Harrison posterior tangent method: which to choose for lateral cervical radiographic analysis. Spine (Phila Pa 1976). 2000;25(16):20722078.

13. Hardacker JW, Shuford RF, Capicotto PN, Pryor PW. Radiographic standing cervical segmental alignment in adult volunteers without neck symptoms. Spine (Phila Pa 1976). 1997;22(13):1472-1480; discussion 80.

14. Jackson RP, McManus AC. Radiographic analysis of sagittal plane alignment and balance in standing volunteers and patients with low back pain matched for age, sex, and size. A prospective controlled clinical study. Spine (Phila Pa 1976). 1994;19(14):1611-1618.

15. Gore DR. Roentgenographic findings in the cervical spine in asymptomatic persons: a ten-year follow-up. Spine (Phila Pa 1976). 2001;26(22):2463-2466.
16. Lee SH, Kim KT, Seo EM, Suk KS, Kwack YH, Son ES. The influence of thoracic inlet alignment on the craniocervical sagittal balance in asymptomatic adults. $J$ Spinal Disord Tech. 2012;25(2):E41-E47.

Corresponding Author: Sakthivel Rajan Rajaram Manoharan, MD, Assistant Professor, University of Alabama Medical Center, FOT 960, 20th Street S, Birmingham, AL 35233. Phone: (205) 9348718; Fax: (205) 975-2319; Email: sakthi.velrajan@ yahoo.com.

Published 3 August 2018

This manuscript is generously published free of charge by ISASS, the International Society for the Advancement of Spine Surgery. Copyright (C) 2018 ISASS. To see more or order reprints or permissions, see http://ijssurgery.com. 